\title{
BILDUNG E A NOTA DE 100 DÓLARES: ANÁLISE DO FILME "QUEM QUER SER UM MILIONÁRIO” SOB A ÓTICA DA FORMAÇÃO PARA OS FRANKFURTIANOS ${ }^{1}$
}

\author{
Lílian Bambirra de Assis² \\ Carolina Assunção Alves ${ }^{3}$ \\ Mariana Geisel Martins ${ }^{4}$ \\ Luana Jéssica Oliveira Carmo
}

http://dx.doi.org/10.1590/1413-2311.216.82326

\begin{abstract}
RESUMO
O objetivo deste artigo é analisar como o sentido da formação para os Frankfurtianos, em especial Adorno, está presente no filme "Quem quer ser um Milionário". Para isso, foi feita uma reflexão sobre a teoria crítica e o conceito de formação para os Frankfurtianos. Utilizando a metodologia de análise fílmica foi possível explicar as reflexões da teoria crítica acerca da formação (Bildung) e semiformação (Halbidung), voz ativa (Mundigkeit), barbárie e desbarbarização. $\mathrm{O}$ contexto apresentado pelo filme realça a dimensão social e cultural dessas categorias e possibilita o esclarecimento de como a formação em sociedade não se restringe aos muros da escola, que, por sua vez, não deve se ater a desenvolver sujeitos adaptados, mas sim preparados para a reflexão crítica e para a transformação.

\footnotetext{
${ }^{1}$ Recebido em 26/04/2018, aprovado em 20/09/2018.

${ }^{2}$ CEFET- MG - Centro Federal de Educação Tecnológica de Minas Gerais - PPGA- Programa de PósGraduação em Administração; Belo Horizonte - MG (Brasil) - lilianbassis@hotmail.com

${ }^{3}$ Centro Universitário de Brasília - UniCEUB. Faculdade de Tecnologia e Ciências Sociais Aplicadas FATECS. Brasília - DF (Brasil) - carolina.alves@uniceub.br

${ }^{4}$ CEFET- MG - Centro Federal de Educação Tecnológica de Minas Gerais - PPGA- Programa de PósGraduação em Administração; Belo Horizonte - MG (Brasil) - marianagmartins@hotmail.com

${ }^{5}$ CEFET- MG - Centro Federal de Educação Tecnológica de Minas Gerais - PPGA- Programa de PósGraduação em Administração; Belo Horizonte - MG (Brasil) - luanajeoli@gmail.com
} 
Palavras-chave: Teoria crítica. Escola de Frankfurt. Análise Fílmica. Formação. Semiformação.

\title{
BILDUNG AND THE \$100 BILL: MOVIE ANALYSIS "SLUMDOG MILLIONAIRE" FROM THE MEANING OF FORMATION TO FRANKFURT SCHOOL
}

\begin{abstract}
The objective of this paper is to analyze how the sense of formation for Frankfurt School, Adorno, is present in the film "Who Wants to Be a Millionaire." For this, a reflection was made about the critical theory and the formation's concept to the Frankfurt School. Using the film analysis methodology was possible to explain the critical theory reflections concerning formation (Bildung), semiformation (Halbidung), active voice (Mundigkeit) and barbarism. The context presented by the film highlights the social and cultural dimension of these categories and enable the understanding of how the formation in society is not restricted to school's walls and the school should not be stuck with development of adapted subjects but be prepared to critical reflection and for transformation.
\end{abstract}

Keywords: Critical Theory. Frankfurt School. Film Analysis. Formation. Semiformation.

\section{BILDUNG Y LA NOTA DE 100 DÓLARES: ANÁLISIS DE LA PELÍCULA "QUIEN QUIERE SER UN MILLONARIO" BAJO LA ÓPTICA DE LA FORMACIÓN PARA LOS FRANKFURTIANOS}

\section{RESUMEN}

El objetivo de este artículo es analizar cómo el sentido de la formación para los Frankfurtianos, en especial Adorno, está presente en la película "Quien quiere ser un millonario". Para ello, se hizo una reflexión sobre la teoría crítica y el concepto de formación para los Frankfurtianos. El uso de la metodología de análisis fílmico fue posible explicar las reflexiones de la teoría crítica acerca de la formación (Bildung) y semiformación (Halbidung), voz activa (Mundigkeit), barbarie y desbarbarización. El contexto presentado por la película subraya la dimensión social y cultural de estas categorías y posibilitan la REAd | Porto Alegre - Vol. 24 - No 3 - Setembro / Dezembro 2018 - p. 1-20 
aclaración de cómo la formación em sociedad no se restringe a los muros de la escuela que, a su vez, no debe atenerse a desarrollar sujetos adaptados, sino preparados para la reflexión crítica y la transformación.

Palabras clave: Teoría crítica. Escuela de Frankfurt. Análisis Fílmico. Formación. Semiformación.

\section{INTRODUÇÃO}

O objetivo do trabalho é analisar como o sentido da formação para os Frankfurtianos, em especial Adorno, está presente no filme "Quem quer ser um Milionário”, utilizando a metodologia de análise fílmica. O uso da análise fílmica na Administração ainda se encontra em estágio embrionário no Brasil. Entretanto, já se encontram catalogados trabalhos que relacionam os filmes com diversas temáticas relativas ao trabalho, às organizações e à sociedade (OLTAMARI; LOPES, 2016). Por meio de alguns trechos do filme são analisados conceitos como: Bildung, desbarbarização, Mundigkeit, experiência e autonomia.

Adorno (1995) entende educação não como modelagem de pessoas, pois não se pode modelá-las a partir do exterior, nem tampouco a mera transmissão de conhecimentos. Para ele, este conceito está relacionado à produção de uma consciência verdadeira. Adorno remete a Kant ao associar a emancipação ao conceito de esclarecimento no sentido de "servir-se do entendimento sem a orientação de outrem" (ADORNO, 1995, p. 169).

Assim, a experiência adquire importância para a superação da alienação do indivíduo. Adorno (1995) ressalta que, apesar da racionalidade ser entendida como capacidade formal de pensar, essa é na realidade uma limitação da inteligência. O sentido mais profundo da consciência só é possível por meio da capacidade de fazer experiências. É essa capacidade que aumenta o nível de reflexão. Entretanto, é preciso deixar claro que o sentido da experiência só se torna um ato de formação quando ultrapassa a simples repetição.

Por essa razão, falar de formação (Bildung) pressupõe algo interno, que está no sujeito e não fora dele. Caso contrário, não se tem uma formação efetiva, mas uma Halbbildung, termo alemão que significa metade de formação, ou semiformação (Halb significa meio ou metade). Se o sujeito não consegue internalizar o conceito e criar seu próprio entendimento, então, a formação não se efetiva de uma maneira completa. Tem-se um sujeito semiformado, capaz de reproduzir apenas aquilo que aprendeu de fora. Nesse sentido, o termo Halbbildung é entendido como semiformação, como a capacidade do sujeito em se adaptar, pois ele só 
entendeu o conceito por fora, e não por dentro, que é o momento do efetivo conhecimento e sua capacidade de autonomia.

Quando o entendimento vem de fora como uma imagem (Bild) externa, o momento da formação consiste em mera reprodução, pois não foi internalizado pelo sujeito. Em uma sociedade reificada e administrada, a experiência formativa é repreendida. Não há espaço para aquilo que não é padronizado, nem para aquilo que não agrega valor.

Em estudos recentes, Maranhão, Santos e Gouveia (2018) afirmam que a situação contemporânea do ensino superior é marcada por uma pedagogia semiformativa. As práticas de ensino se apresentam interiorizadas pelos interesses capitalistas. Há uma falta de elementos que sustentem uma educação autônoma e consciente. A educação, que deveria ser a chave para a saída desse ciclo, ao permitir a capacidade da autorreflexão, acaba por se tornar a principal via de empobrecimento pedagógico. Os resultados das instituições são medidos pela quantidade de alunos que se matriculam e que se formam, respondendo aos imperativos do mercado. Nesse sentido, as instituições de ensino se tornam tributárias do sistema capitalista. Quanto mais o sujeito se ajusta aos interesses do capital, mais produtivo ele se torna. O que se vê é então um ambiente tomado pela semiformação (MARANHÃO; SANTOS; GOUVEIA, 2018).

Maar (1995; 2003), toma como referência o processo de formação em Adorno para enfatizar que a experiência como ato de emancipação ocorre quando permite ao sujeito o confronto entre a realidade e o conceito, o que leva à reflexão e à autonomia de pensamento. Para elucidar melhor estas e outras questões, optou-se por analisar o filme "Quem quer ser um Milionário".

Utilizar o filme como um campo fértil para uma análise crítica da sociedade pode contribuir com os estudos organizacionais, uma vez que há, de acordo com Maranhão e Vilela (2017), certo menosprezo por pesquisas empíricas com o aporte das teorias frankfurtianas na área da administração. Os autores defendem a imanência entre teoria crítica e pesquisa empírica para auxiliar a compreensão de diversos fenômenos ainda pouco desenvolvidos.

De acordo com Goliot-Lété e Vanoye (1992), o filme é um produto cultural inserido num contexto sócio-histórico e fornece representações que remetem direta ou indiretamente à sociedade na qual se inscreve. Ele apresenta um ponto de vista sobre um traço da contemporaneidade e estrutura em espetáculo uma representação da sociedade ao mostrar um sistema de papéis ficcionais e sociais; a organização de suas relações; a concepção do tempo e as reações que pretende mobilizar no espectador.

REAd | Porto Alegre - Vol. 24 - No 3 - Setembro / Dezembro 2018 - p. 1-20 
A análise de um filme interage com as significações, e implica dividi-lo em partes, decodificar, desconstruir, para depois estabelecer relações entre os elementos que foram isolados, ou seja, reconstruir o filme. A desconstrução equivale à descrição, enquanto a reconstrução corresponde à fase de interpretação. Os instrumentos metodológicos utilizados neste estudo pertencem ao domínio da Análise do Discurso da Teoria Semiolinguística de Charaudeau $(1983 ; 2001)$.

Após esta introdução, apresenta-se o percurso teórico que subsidiou a pesquisa. Em seguida, será explicada a metodologia utilizada, para então proceder à análise dos dados, e, finalmente, apresentar as considerações finais.

\section{PERCURSO TEÓRICO}

\subsection{A TEORIA CRÍTICA}

Com a Dialética do Esclarecimento, Adorno, juntamente com Horkheimer, passa de uma teoria critica em geral para uma teoria crítica da sociedade, o que aflora temas relacionados à sociedade industrial - alienação, indústria cultural (PUCCI, 1994). O interesse de Adorno e Horkheimer estava voltado para áreas como a cultura, a sociedade e a psique humana, além de analisar problemas como a estrutura e o desenvolvimento da autoridade, a proliferação da cultura de massas, as questões do indivíduo, do cotidiano e da liberdade.

Para Kant (1985), o esclarecimento (Aufklärung) é a saída do homem da menoridade. A menoridade é entendida como a incapacidade do sujeito de ter seu próprio entendimento sem a direção de outro sujeito. O filósofo colocava no sujeito a responsabilidade pela sua libertação, isto é, cabe ao sujeito ter a coragem de servir-se de si mesmo e de fazer uso de sua própria razão.

Horkheimer e Adorno (1991) acreditavam que a razão iluminista desenvolvida pela burguesia no início da era moderna, continha as dimensões emancipatória e instrumental, estando a segunda integrada e à serviço da primeira. $\mathrm{O}$ problema é que à medida que a burguesia começa a impor seu domínio a outras classes, a dimensão emancipatória da razão vai sendo ofuscada. A ciência, a tecnologia e o conhecimento pensados inicialmente para minimizar o sofrimento do homem vão perdendo o seu caráter libertário.

É assim que a sociedade unidimensional, liderada pelos técnicos e ciência se transformou em instrumento de dominação e reprodução. Pucci (1994), cita Adorno e Horkheimer (1991) ao caracterizar a razão instrumental. Ele mostra que a exigência de "pensar o pensamento" foi deixada de lado. A razão instrumental passa a ser a razão no 
processo técnico. Reifica-se, coisifica-se. Bassani e Vaz (2008) refletem sobre esse processo de coisificação que aproxima as pessoas de máquinas.

O "pensar o pensamento" não foi apenas deixado de lado, mas tentaram erradicá-lo, uma vez que o sistema não pode correr o risco de ser questionado. Nesse sentido, Horkheimer e Adorno (1991) mostram que, para o positivismo, que ocupou o lugar da razão esclarecida, o mundo dos inteligíveis não é apenas proibido, como também é visto como uma loucura.

Jay (1988) lembra que a dimensão instrumental da razão aparece também na negação da arte, que seria genuinamente um momento utópico que aponta para uma transformação social e política. É por isso que existe em Adorno (1991) uma relação direta entre o estético e o social.

É banindo a razão emancipatória e transformando a racionalidade técnica na racionalidade da dominação, que o saber passa a ser sinônimo de poder. Nesse sentido, Horkheimer e Adorno (1991) afirmam que a essência do Iluminismo é a dominação, na medida em que pode manipular os homens. Segundo estes teóricos frankfurtianos, a razão emancipadora do Iluminismo, que queria livrar o homem do mito, transforma-se no próprio mito, recaindo na mitologia da qual nunca soube escapar: a uniformização, enfim, o mundo administrado. Uma manifestação exemplar da razão instrumental é a Indústria Cultural.

Segundo Adorno (2009) o sujeito abstrato, ou semiformado (Halbbildung) não é capaz de enfrentar a dialética da formação em um mundo imerso na Indústria Cultural. Ao contrário, o sujeito concreto (Bildung) consegue estabelecer um diálogo com as instâncias semiformativas, pois ao mesmo tempo em que se adapta, é desafiado a criar seus esquematismos, sob o risco de interpretar o mundo com os esquemas prontos da Indústria Cultural, buscando alternativas de vida social. Ao se adaptar e emancipar realiza o projeto do esclarecimento. Mas, afinal, o que significa a Formação para os Frankfurtianos?

\subsection{FORMAÇÃO PARA OS FRANKFURTIANOS}

O conceito de formação desenvolvido pelos frankfurtianos, principalmente por Adorno, aparece em diversos artigos que compõem a coletânea organizada em 1971 por Kadelbach, traduzida como Educação e Emancipação. Em alguns desses textos, tais como Educação para que? e A Educação pós Auschwitz, Adorno (1995) desvela o sentido do que vem a ser a educação ao fazer distinção entre semiformação e formação.

Segundo Cohn (1986), a educação só teria pleno sentido como educação para a autorreflexão crítica. Percebe-se que, para Adorno (1995), a educação cultural só tem 
sentido se for para buscar autonomia, a autodeterminação kantiana e superar os limites estabelecidos pela barbárie. Assim, a educação é, antes de tudo, esclarecimento.

É diante do que Adorno vivenciou que ele afirma que todo processo educacional deve sempre pensar em Auschwitz, pois a barbárie mostra que ela se desenvolve quando todos os processos de formação desenvolvidos pela escola fracassam (RAMOS DE OLIVEIRA, 1992). A barbárie deseduca, por isso, é preciso reeducar, e reeducar significa desbarbarizar. Uma das formas identificadas por Zuin (1992) para a desbarbarização é a saída de uma dimensão de ignorância para o conhecimento, para o esclarecimento crítico. Para Adorno (1995), a educação tem uma importância essencial na questão da formação das gerações atuais, na busca pela autonomia e emancipação.

Por essa razão, quando Adorno (1995) responde a pergunta “Educação para quê?”, ele diz "para a produção de uma consciência verdadeira". Em algumas oportunidades ele utiliza o termo Mündigkeit, que significa voz ativa, falar pela própria boca, adquirir a maioridade kantiana. O uso autônomo da razão para Kant é a Mündigkeit de Adorno.

É seguindo a mesma lógica que os sistemas educacionais deveriam desempenhar dois papéis: o social, preparando o aluno para se integrar e adaptar à sociedade; e o individual, permitindo ao aluno desenvolver a autorreflexão. Ou seja, o papel da educação não seria apenas o de promover a adaptação, mas também de permitir ao aluno desenvolver a resistência (ADORNO, 1995).

Adorno (1995) entende a educação não como modelagem de pessoas, pois não se pode modelá-las a partir do exterior, nem tampouco a mera transmissão de conhecimentos. Para ele, esse conceito está associado à produção de uma consciência verdadeira. Ao remeter a Kant, Adorno (1995) associa emancipação ao conceito de esclarecimento, ou seja, "servirse do entendimento sem a orientação de outrem" (ADORNO, 1995, p. 169).

Nesse sentido, o autor afirma que o conceito de emancipação é abstrato e relacionado a uma lógica dialética: adaptação e resistência. Ao mesmo tempo em que a educação seria impotente se ignorasse o objetivo de preparar o homem para se orientar no mundo, ela também seria questionável se produzisse somente sujeitos ajustados à realidade.

Assim, a experiência adquire importância para a superação da alienação do indivíduo. Adorno (1995) ressalta que o sentido mais profundo da consciência está relacionado à capacidade de vivenciar experiências. É essa capacidade que aumenta o nível de reflexão. Entretanto, é preciso deixar claro que o sentido da experiência só se torna um ato de formação quando ultrapassa a simples repetição. 
Por isso Maar (1995; 2003) tendo como referência o processo de formação em Adorno, enfatiza que a experiência como ato de emancipação ocorre quando permite ao sujeito o confronto entre realidade e conceito, o que leva à reflexão e à autonomia de pensamento. Segundo o autor, "a emancipação como "conscientização" é a reflexão racional pela qual o que parece ordem natural, "essencial" na sociedade cultural, decifra-se como ordem socialmente determinada [...]" (MAAR, 2003, p. 472).

Apesar da importância da questão política na educação, Adorno (1996) ressalta que, em sociedades altamente industrializadas, como a do capitalismo tardio, a formação está ligada à formação para o trabalho. E quando não se tem a autorreflexão, não se pode falar de formação, mas sim de semiformação. É nesse sentido que a racionalidade instrumental que permeia a cadeia produtiva chega à área de educação e impõe ao sujeito a necessidade de adaptação para que se integre ao processo. Entretanto, essa integração significa em alguns casos uma perda da capacidade crítica e de reflexão.

É nessa situação em que o sistema educacional se encontra hoje. As novas tecnologias estão se tornando protagonistas na função de formar pessoas de forma padronizada. Os alunos são bombardeados de informações que contém opiniões prontas, o que os distancia da possibilidade de autorreflexão e consciência crítica, propostas por Adorno. Essas informações são enviesadas pelos interesses do sistema capitalista. As instituições educacionais se tornam fábricas de indivíduos produtivos e alienados. Trata-se de verdadeiras práticas pedagógicas de semiformação (MARANHÃO; SANTOS; GOUVEIA, 2018).

Diante de todo o exposto, cabe, conforme o próprio Adorno esclarece em sua dialética negativa, resgatar o conceito pelo conceito. Para clarear ainda mais o sentido da formação, a partir de tudo o que foi colocado sobre adaptação e resistência, serão explicados os termos em alemão que descrevem o que foi dito: Bildung e Halbbildung.

Ramos de Oliveira (1998), para explicar o sentido de Bildung, resgata em Benjamim, outros dois termos por ele utilizados Erlebnis e Erfahrung. O primeiro reflete uma pessoa que passa pela vida como um expectador, como alguém que apenas reage a estímulos. Já o segundo termo refere-se a alguém que exerce um grau de reação consciente, que modifica, ou seja, capaz de viver a experiência formativa, sentir e se expressar, e não simplesmente colecionar fatos sobrepostos.

Bildung refere-se à autonomia e adaptação, revelando a tensão entre a liberdade do sujeito e sua necessidade de configurar-se à vida real (PUCCI, 1998). Essa tensão fica mais clara quando se entende o conceito de Das Bild, que traduzido para o português significa "figura". O que se traduz como formação, vem na realidade da imagem. Isso significa que é 
algo interno, a imagem no interior do sujeito, é a abstração que ele faz, é a figura que ele memoriza.

Por essa razão, falar de formação (Bildung) pressupõe algo interno, que está no sujeito e não fora dele. Caso contrário, não se tem uma formação efetiva, mas uma Halbbildung, uma semiformação. Isso porque se o sujeito não consegue internalizar o conceito, criar sua própria imagem, seu próprio entendimento, e desse modo, a formação não se efetiva de uma maneira completa. Tem-se pela metade, uma vez que ele será capaz apenas de reproduzir aquilo que aprendeu de fora. Nesse sentido, o termo Halbbildung é entendido como a capacidade do sujeito em se adaptar, pois só entendeu o conceito por fora, e não por dentro, que é o momento do efetivo conhecimento e sua capacidade de autonomia. Quando o entendimento vem de fora, com uma imagem (Bild) externa, o momento da formação é mera reprodução, pois não foi internalizado. O sujeito reproduz, neste caso, a imagem do outro e não sua própria, ou seja, não tem autonomia.

Offe (1990) se baseia nas ideias de Adorno para fazer uma importante diferenciação entre semiformação e ignorância. Essa última ocorre quando se tem o desconhecimento do sujeito sobre determinada questão. A Halbbildung, entretanto, é pior, pois os sujeitos têm a impressão de que conhecem e, ao achar que já o sabem, perdem a curiosidade sobre o real. Assim, enquanto a ignorância está ligada ao desconhecimento, a semiformação está associada à deformação da realidade, que se apresenta como única possibilidade. Duarte (2003, p. 445), ao refletir sobre a Teoria da semiformação, enfatiza ainda que a semiformação não refere-se a falta de cultura, mas a uma anulação de "possibilidades libertadoras até mesmo da incultura".

Para que a experiência formativa ocorra, ou seja, a possibilidade do sujeito em adquirir um juízo autônomo a respeito de algo, é necessário tempo de mediação e continuidade (ADORNO, 1995).

Giroux (1997) lembra que a inaptidão à experiência formativa é reforçada pelos sistemas formais e informais de avaliação nas escolas e pelo entendimento do papel da escola, normalmente vista como uma instituição de formação de mão de obra para o sistema capitalista. É nesse sentido que Maar (1995) conclui que a crise do processo formativo é inevitável na dinâmica atual do processo produtivo.

Adorno (1995) lembra que a formação crítica não é fenômeno restrito aos muros das escolas. Ao contrário ela faz parte da formação cultural do sujeito: formação de personalidade e intersubjetividades. 
Colocadas essas questões, e fazendo uma crítica imanente, aceitando a priori que a formação não se efetiva apenas nas universidades ou escolas, como o sentido de formação para os frankfurtianos está presente no filme “Quem quer ser um milionário?”?

\section{MÉTODO}

De acordo com Goliot-Lété e Vanoye (1992), o filme é um produto cultural inserido num contexto sócio-histórico, e, portanto fornece representações que remetem direta ou indiretamente à sociedade na qual se inscreve. Constrói um mundo possível em relação com o mundo real em que está inserido, reafirma ou contesta esse mundo, ao mostrar um sistema de papéis ficcionais e sociais; a organização de suas relações e as reações que pretende mobilizar no espectador.

A análise de um filme mexe com as significações, e implica dividi-lo em partes, decodificar, desconstruir, para depois estabelecer relações entre os elementos que foram isolados - reconstruir o filme. A desconstrução equivale à descrição, enquanto a reconstrução seria a interpretação. Como bem esclarece Penafria (2009), analisar um filme requer a definição de objetivos, pois a diversidade de possibilidades permite que ele seja estudado a partir de vários aspectos como a linguagem, a estética, as temáticas, entre outros. Estes elementos conduzem a percursos divergentes, porém não excludentes, mas sim complementares na compreensão do papel discursivo e social desempenhado por um filme.

É preciso esclarecer ainda que os instrumentos metodológicos a serem utilizados neste estudo pertencem ao domínio da Análise do Discurso, mais especificamente da Teoria Semiolinguística, de Charaudeau $(1983 ; 2001)$. Esse autor define a comunicação como uma relação contratual, constituída e restringida por três componentes. $\mathrm{O}$ primeiro, comunicacional, corresponde às circunstâncias materiais em que se realiza o ato de linguagem. O segundo, psicossocial, compreende a identidade possivelmente reconhecidos pelos sujeitos entre si. O terceiro e último, intencional, consiste no conhecimento a priori possuído pelos participantes, um sobre o outro, que direciona a finalidade do discurso.

A teoria permite entender que todo ato de linguagem envolve uma interação de intencionalidades, na qual cada participante tem uma expectativa de significação particular que influencia o resultado da troca linguageira. Ademais, o ato de linguagem é produto da ação de seres psicossociais, testemunhas das práticas sociais e representações imaginárias da comunidade à qual pertencem. Esses seres são sujeitos pensantes, produtores de significações linguageiras, e para os quais tais significações retornam, a fim de constituí-los. $O$ ato de 
linguagem é ainda uma encenação, em que o locutor se apropria dos componentes do dispositivo de comunicação em função dos efeitos de sentido que pretende causar no interlocutor.

O universo cinematográfico requer a atenção a elementos que determinam a orientação do discurso fílmico. Logo, ao analisar um filme sob o ponto de vista discursivo, é preciso levar em conta, junto com os objetivos, todos esses elementos do cinema (ALVES, 2011):

- Atos de linguagem constituídos por uma série de códigos semiológicos que envolvem o roteiro, a captação, a distribuição e a projeção de imagens e sons em movimento, com o objetivo de comunicar, e que envolvem a participação de sujeitos sociais nas instâncias de produção e recepção;

- Cadeias de atividades que agrupam a realização e a comercialização de filmes, o que remete ao caráter industrial e cultural ligado à comunicação de massa;

- Manifestações artísticas portadoras de especificidades estéticas e discursivas, cujas recorrências podem constituir tendências ou escolas;

- Espaços físicos programados para a exibição de filmes.

Enquanto gênero discursivo ficcional, o filme narrativo de ficção cria um mundo paralelo. Uma relação de comunicação que se desdobra: por um lado, tem-se a autoria do filme, uma expectativa sobre para quem ele é direcionado; por outro, tem-se o enredo, em que as personagens participam de encenações do ato de linguagem, com todas as características típicas representadas ali. E, apesar da história seguir o curso sem que o espectador possa agir diretamente sobre ela, ela existe para esse mesmo espectador.

Deve-se observar que o filme é um produto de autoria coletiva, embora submetido principalmente ao projeto de fala do roteirista e do diretor. O processo de interpretação efetivo só pode ser verificado em estudos de recepção. Por toda essa complexidade é que a análise fílmica demanda clareza quanto àquilo que se pretende examinar. Para o presente trabalho, a meta é discutir conceitos teóricos e tentar visualizá-los com a ajuda de um filme, a fim de aprimorar a reflexão. Quem quer ser um milionário?, de Danny Boyle, serve às demarcações da teoria crítica apresentadas anteriormente, principalmente o conceito de formação (bildung).

Estamos cientes de que não se trata de um exemplo palpável, concreto das ideias desenvolvidas por Adorno, o que não impede que o filme seja um ponto de partida para a melhor apreensão do conceito e subsequente possibilidade de aplicação ao mundo real, o que poderá ser feito em estudos futuros. Também não se trata de elaborar nenhuma crítica do 
filme e, portanto, não é o caso de avaliá-lo. Antes de introduzir a análise, vale reiterar que pretendemos simplesmente buscar auxílio ilustrativo à abordagem das categorias apresentadas pelos autores da teoria crítica.

\section{QUEM QUER SER UM MILIONÁRIO?}

O filme se passa em um contexto de pobreza e mostra a história de Jamal, um órfão que viveu até os 18 anos nas favelas de Mumbai, onde trabalha como garçom de um call center. Sem quase nenhum estudo, ele tem a chance de mudar completamente de vida ao participar do jogo Who wants to be a millionaire?, e ganhar 20 milhões de rúpias indianas. Para vencer, ele precisa acertar todas as perguntas do programa televisivo sobre cultura geral. O desempenho do jovem provoca desconfiança: como um rapaz sem acesso à educação consegue tal proeza que nem homens letrados alcançaram? Preso e torturado em busca de uma confissão de fraude, na véspera do decisivo programa, o já ganhador de 10 milhões de rúpias revela a fonte das respostas bem-sucedidas: a experiência vivida. Para cada questão, um flashback biográfico mostra como Jamal recuperou, em amargas memórias, as informações solicitadas pelo apresentador.

Uma vez que esta discussão está calcada na Teoria Crítica não negligenciamos o fato de que o filme faz parte da Indústria Cultural, com objetivos de grande público e lucro em bilheteria. Ele segue padrões voltados para esse fim, como a inserção de uma cena de ação nos minutos iniciais para cativar o espectador (segundo o próprio diretor), quando as crianças que jogam críquete fogem da polícia. Prova disso são o carismático universo infantil da brincadeira e a montagem alucinante em estilo videoclipe. O filme atende a outros prérequisitos de meio de comunicação de massa: apesar de não ser uma megaprodução hollywoodiana, foi financiado por grandes produtoras.

No entanto, há também indícios que permitem a conexão entre as representações presentes na narrativa e a ideia de formação em Adorno. Voltar a atenção para os autores, especialmente Swarup, que assina a versão literária, e Boyle, que transportou o romance para o cinema, já permite uma primeira aproximação. Em entrevista à imprensa francesa (Le Figaro, 19/02/2009), Swarup declarou que os temas do livro, conservados em princípio pelo filme, são a esperança e a sobrevivência: "Eu queria mostrar que o conhecimento não é reservado a uma elite bem educada e que mesmo uma criança das ruas pode usar a sabedoria para ganhar um jogo.” (tradução livre).

REAd | Porto Alegre - Vol. 24 - No 3 - Setembro / Dezembro 2018 - p. 1-20 
A inspiração para a criação do protagonista vai ao encontro da questão dialética da formação, pois Jamal se assemelha ao sujeito concreto que, em diálogo com as instâncias semiformativas da Indústria Cultural, consegue se adaptar e buscar alternativas, se emancipar. Além de não ter se tornado um criminoso, é possível afirmar que, simbolicamente, no nível discursivo, ou seja, no mundo da ficção, ele consegue mudar o rumo da própria vida e realizar o projeto do esclarecimento.

Em declarações à imprensa, Boyle classificou o filme como um conto de fadas com amor romântico cuja consumação é travada pelos obstáculos do destino até o final feliz; em que os frágeis conseguem se fazer ouvir e o bem triunfa. Entretanto, o fabuloso inverossímil recebe o contrapeso dos elementos de realidade: filmagens em locações verdadeiras da cidade de Mumbai como as favelas, o prostíbulo e a estação de trem, sem isolamento especial dos espaços para as cenas, quase sempre durante o cotidiano normal; trilha musical original composta por músico do país; além de elenco e figurantes oriundos das favelas representadas na ficção. Tais aspectos colaboram para que o filme remeta, mesmo que de maneira distorcida, a uma reflexão sobre a realidade da população em questão. Motivo pelo qual o diretor foi, ao mesmo tempo, glorificado por aqueles que se sentiram orgulhosos da Índia mostrada na tela, e crucificado pelos que condenaram os exageros em uma estigmatizante "pornografia da pobreza".

A montagem cria uma estrutura narrativa de base tripla, com idas e vindas ao tempo e no espaço entre os momentos de participação no programa de TV, o interrogatório na delegacia de polícia e as memórias de Jamal. Tal costura apresenta ao espectador a trajetória do personagem no sentido do que podemos identificar, conforme a Dialética Negativa, como esclarecimento e uso da voz ativa (mundigkeit) resultantes da interação com a realidade social. Tentaremos aprofundar um pouco mais essa relação com a análise de sequências específicas.

\subsection{BILDUNG E A NOTA DE 100 DÓLARES}

O conceito de formação a partir da experiência (bildung) será discutido com a ajuda de uma sequência de quase sete minutos, aos $45^{\prime}$ de filme, onde o deslocamento triplo da narrativa (TV-delegacia-biografia em flashback) ilustra a definição de Adorno. Na televisão, Jamal deve dizer qual político importante está retratado na nota norte-americana de 100 dólares. Os enquadramentos, a montagem e o som seguem o formato original de Who wants to be a millionaire?, em plano e contra-plano, com primeiro plano nos momentos de maior 
emoção. Há também uma inserção do que acontece nos bastidores, com reações dos profissionais que trabalham na emissão. Na delegacia, ele é obrigado a esclarecer como e por que conhece a resposta, o que leva à reconstituição de um acontecimento da adolescência gravado na memória do protagonista. Com relação à linguagem cinematográfica, vale ressaltar que o fato do delegado estar de pé e Jamal sentado enfatiza a relação vertical de superioridade do policial e inferioridade do rapaz.

Contudo, Jamal não se deixa intimidar. No estúdio, o apresentador é irônico ao questionar se o garoto costuma ver essa quantia em dinheiro. Este responde à altura, com deboche, dizendo que recebe como gorjeta mínima. O mesmo acontece em seguida com o delegado. Enquanto eles assistem a uma gravação desse momento do programa, o policial interroga quem está na moeda de mil rúpias, mas Jamal diz não saber algo tão óbvio para qualquer indiano - talvez devido ao estresse pelos impactos da tortura. Ao ver o rosto de Gandhi na cédula exibida pelo delegado, Jamal desdenha do mártir. Como punição, recebe nova ameaça de eletrochoque.

As cenas no programa e na delegacia e as relações estabelecidas entre os personagens nos remetem à crença alienada na semiformação, ou seja, na simples formação para o trabalho como mercadoria, cuja pressão social, sem autorreflexão crítica, acomodados em uma ideologia dominante que associa cultura e poder. As potencialidades de quem não teve acesso à educação parecem vislumbrar uma modelagem padronizada de fora para dentro e, portanto, equivocada segundo Adorno. Porém, os dois diálogos revelam que, apesar do contexto e das dificuldades sociais, pode haver formação pela capacidade de reflexão via experiência.

Quanto ao flashback que explica o conhecimento do jovem indiano, os códigos semiológicos fílmicos se encarregam das simbologias esclarecedoras do percurso emancipatório do garoto. Planos gerais da cidade situam Jamal e o irmão Salim ao longo dos dias em Mumbai. A variação das imagens dos dois irmãos em diversos pontos urbanos mostra o estilo de vida andarilho, os lugares por onde eles passaram e adquiriram vivência. Ambos crescem com a cidade, de um jeito enviesado. Simultaneamente ao desenvolvimento expresso pela construção civil, pelos arranha-céus, também estão sujeitos às marcas da pobreza das favelas e do caos do trânsito.

$\mathrm{Na}$ sequência das imagens externas, os irmãos trabalham na cozinha de um restaurante. $\mathrm{O}$ espectador recebe mais informações via linguagem cinematográfica: pelos planos, percebe-se que eles são os únicos adolescentes entre os funcionários. São órfãos que não contam com os cuidados de nenhum adulto e precisam de emprego. Enquanto 
conversam, Salim já se ocupa com naturalidade de contravenções como encher uma garrafa de água da torneira e colar a tampa para falsear um produto novo. Jamal, concentrado no trabalho, só pensa em encontrar sua amada Latika. Sendo essa busca que o leva ao conhecimento sobre a nota de 100 dólares.

Ao caminhar por uma passagem subterrânea, Jamal reencontra o garoto que foi cegado pelo explorador de crianças de quem ele e o irmão haviam fugido, quando Latika foi recapturada. O menino perdeu a visão porque cantava bem, e renderia esmolas melhores aos exploradores se não pudesse enxergar. Isso conduz a reflexão de até que ponto a dominação dos interesses do capital pode chegar. O filme mostra que o explorador furou os olhos do garoto para ganhar mais, mas trazendo para a realidade, o quanto o sistema educacional está mutilando os sujeitos a capacidade de "pensar o pensamento"? A sociedade, imbuída dos interesses capitalistas "furam" não os olhos, mas as mentes, a possibilidade de pensar e reflexão autônomos dos sujeitos. Resta apenas se ajustar com o que sobra.

Por causa da mutilação sofrida, ele foi obrigado a desenvolver os outros sentidos. Pelo olfato, o garoto reconhece o dinheiro dado por Jamal como dólar. Pelo tato e pela audição, ele reconhece o amigo. Pela experiência, ele conhece a descrição de Benjamin Franklin e a relação com a cédula de 100 dólares. E é por essa experiência vivida e transmitida a Jamal, que ele sabe a reposta correta para o programa de TV. Mais uma vez, estamos diante de um exemplo de bildung, nas imagens que o sujeito cria a partir do próprio interior em contato com o mundo, e que passam também a constituí-lo em repertório cultural e social.

\subsection{MUNDIGKEIT}

Jamal: E porque eu sou da favela, um garçom, eu sou um mentiroso? Delegado: A maioria de vocês são.

O diálogo acima é um exemplo adequado para se discutir a questão da voz ativa (mundigkeit) na teoria crítica. Se o uso autônomo da razão é o que permite ao sujeito se emancipar e produzir uma consciência crítica verdadeira, o filme nos traz a representação dessa consciência e dessa voz. O delegado reitera a fala do rapaz: por ser da favela e garçom, espera-se que ele fosse um mentiroso. Ou seja, o equívoco dos estereótipos e das moldagens de uma semiformação baseada na promoção de indivíduos adaptados leva o delegado a subestimar o jovem em função da classe social, mas é a própria autonomia do garoto que faz 
com que o policial mude de ideia. Ao contar a própria vida durante o interrogatório, ele convence de que é diferente da noção subjugadora do interlocutor.

Antes dessa conversa, em outro flashback, Jamal oferece mais uma prova de autonomia perante uma armadilha preparada pelo apresentador do programa de televisão. A sequência de aproximadamente seis minutos mostra a penúltima pergunta feita ao garçom de call center. Durante o intervalo do programa, no vestiário do estúdio, o animador conversa com ele. A iluminação é sombria com poucas luzes, e destaque para a fumaça do cigarro do apresentador; privilegiam-se os planos mais fechados, que mostram a tensão psicológica e dramática da cena. É como se Jamal estivesse diante da proposta de um pacto diabólico.

A imagem invertida do menino refletida por um espelho, faz com que ele apareça de ponta cabeça na tela, simboliza o momento de confusão mental: além de não saber a resposta para a próxima pergunta, ele está sendo assediado pelo "dono do show". É interessante notar que por muitas cenas, pensa-se como é mais fácil se deixar dominar, aceitar aquilo que está sendo proposto, já que o poder ou a dominação do "dono do show" parece superar em muito a capacidade de pensar livremente de Jamal. Isso que ocorre com a educação na sociedade contemporânea. É mais fácil se ajustar do que questionar.

Também é significativo o fato de o apresentador se comparar ao slumdog enquanto urina e afirma que, como o garoto, ele também foi um excremento da sociedade e mudou de vida. Graças ao dinheiro e ao status, passou a pertencer a um nível mais alto. Os interesses do capital podem elevar qualquer pessoa de um excremento da sociedade a um "dono do show", basta se conformar, basta aceitar o que lhe é imposto sem questionamentos.

Ao sair do banheiro, Jamal percebe que o homem deixou uma sugestão de resposta no espelho: letra B. Neste momento, a luz da cena fica mais clara, como se o rapaz estivesse sendo iluminado. Mais tarde, as ações dele revelam ao espectador que a luz foi, na verdade, "desconfiar da esmola". Ao escolher a letra D como resposta, surpreende o apresentador, que ainda tenta fazer com que ele mude de ideia. Nessa cena percebe-se a representação da voz ativa. Em vez de aceitar a informação veladamente imposta com o objetivo de prejudicá-lo, Jamal reconhece o disfarce e consegue novamente se sair bem no jogo. Demonstra possuir autonomia e voz ativa para recusar a manipulação - qualidades adquiridas longe da escola, por uma consciência resultante da experiência e da interação social.

REAd | Porto Alegre - Vol. 24 - No 3 - Setembro / Dezembro 2018 - p. 1-20 


\section{CONSIDERAÇÕES FINAIS: ENTRE A BARBÁRIE E A DESBARBARIZAÇÃO}

Todo o contexto econômico, cultural, social e político em que o filme se desvela nos conduzem à oposição entre os conceitos de barbárie e desbarbarização de Adorno. De um lado a barbárie, representada por pessoas produtos de um meio em que os processos de formação escolar fracassam e que se deixam levar pelo determinismo da própria história de vida em risco social. De outro lado a desbarbarização, representada por meio da passagem da ignorância para o conhecimento pelo esclarecimento crítico, pela emancipação pelo uso da razão e do afeto. As experiências via interação social podem conduzir ao mundo marginal do crime ou podem ser usadas no acúmulo de capital pessoal e social para seguir um rumo diferente.

No filme há uma sequência emblemática que facilita a compreensão desses conceitos; é o momento decisivo na vida de Salim e Jamal: a morte da mãe, aos 15 minutos de filme, episódio que deu a Jamal a resposta a uma pergunta do jogo televisivo sobre o Deus Rama da mitologia hindu. Por causa da disputa religiosa entre hindus e muçulmanos, o local onde a família mora é violentamente invadido por um grupo. Durante o massacre, a mãe de Jamal é assassinada na frente dos filhos e ordena que eles corram. Enquanto ela é agredida, os irmãos se ajudam para sair do poço em que brincavam, e começam uma fuga desesperada em meio aos ataques. É durante a fuga que Latika, o par romântico de Jamal, aparece pela primeira vez no filme, como se a perda materna estivesse para ser compensada pela chegada do amor, o que é uma construção cultural e histórica.

A ação é enfatizada pelas imagens de câmera no ombro, cortes rápidos de montagens, planos em movimentos desordenados e acelerados pela edição digital, som ambiente de gritos e pancadas, além de uma música que evoca, ao mesmo tempo, suspense, aventura e drama. No entanto, chama atenção o uso do slow motion em um plano que flagra as duas crianças no exato instante em que a mãe é morta. A desaceleração da imagem revela que a visão do assassinato será, além de um trauma insuperável (daí o uso do tempo lento em que o momento é congelado), o divisor de águas na vida de ambos.

$\mathrm{Na}$ cena seguinte, após se encontrarem em um esconderijo, eles se abrigam da chuva. Latika está de pé, do lado de fora, exposta à tempestade. Jamal quer acolhê-la para que ela seja o terceiro mosqueteiro, mas Salim não permite e diz ser o chefe da família, quem toma as decisões. O maior vira-se de lado e finge dormir, mas os olhos arregalados em planos mais próximos, intercalados com imagens em flashback da mãe durante o ataque (que na cena analisada tornam-se o pesadelo de Jamal e a memória insone de Salim), mostram que ele está 
em transformação devido ao trauma do dia. Em mais uma demonstração da própria autonomia e num gesto de generosidade, Jamal desobedece ao irmão e recebe a menina no esconderijo, enquanto uma melodia romântica indica a fábula de amor que acaba de começar. Nesse momento, Salim continua acordado, mas não impede o caçula, pois parece vidrado nos próprios ressentimentos.

A partir daí, a relação fraterna é marcada pelo instinto protetor do mais velho sobre o mais novo, devido aos laços de família. Mas, para tudo o que resta, Salim transforma-se num fora da lei autocentrado, preocupado apenas em salvar a própria pele, sem se importar com as consequências. Por se tratar de uma narrativa que segue os moldes do conto de fadas, a punição do mal que ele representa e a redenção ao se sacrificar por Jamal acontecem no desfecho. Ao longo da história, porém, Salim dá muitos exemplos de que sucumbiu ao se adaptar à realidade que lhe foi imposta e repeti-la, ao assumir o posto de matador e capanga de criminosos. Um retrato da barbárie, tal como definida por Adorno.

Jamal é exatamente o oposto, a desbarbarização. Submetido aos mesmos traumas e restrições que o irmão, ele é capaz de confrontar realidade e conceito, refletir, ter o próprio pensamento, e não se conformar em apenas se adaptar. Ele transforma o caminho percorrido ao absorver as experiências vividas de maneira produtiva e positiva, no sentido de deixar que a cultura e a sabedoria adquiridas ao longo dos anos lhe favoreçam num jogo de televisão. Jamal está longe de preencher qualquer requisito para o que Adorno definiu como fetiche do talento, ou seja, o dom para o sucesso conformado aos padrões do capitalismo tardio. A maneira como o garoto lida com os desafios impostos (na vida e no jogo) revela o quão verdadeiramente talentoso ele é.

Assim, o filme nos aproxima e nos faz refletir sobre contextos que distanciam e dificultam a possibilidade de autorreflexão e consciência crítica diante da pressão social e cultural vividas. As categorias de Erlebnis e Erfahrung de Benjamim retomadas por Adorno são representadas nas vivências do filme. A categoria Erlebnis é representada por passantes pela vida, espectadores do próprio destino, conformados, resignados a se sucumbir a realidade social na qual estão inseridos. Erfarung, é representada por aqueles que, conscientes da própria realidade, são capazes de reagir, questionar o meio social de modo a tentar reconfigurá-lo.

O filme Quem quer ser um milionário? é um exemplo para explicar as reflexões da teoria crítica acerca da formação (bildung) e da semiformação (halbidung), da voz ativa (mundigkeit), da barbárie e da desbarbarização, experiência e autonomia. Tudo isso no sentido de esclarecer como a formação do indivíduo não se restringe aos muros da escola que, 
por sua vez, não deve se ater a desenvolver sujeitos adaptados, mas sim preparados para a reflexão crítica e, quando for o caso, para a transformação. O trabalho realizado além de elucidar os temas a que se propõe, deixa claro como a metodologia de análise fílmica pode ser aplicada como uma forma alternativa de estimular o entendimento de diferentes temas, em especial aqueles relacionados à Teoria Crítica.

\section{REFERÊNCIAS}

ADORNO, T.W. Erziehung zur Mündigkeit. Suhrkamp, 1971.

ADORNO, T. W. Educação e Emancipação. Rio de Janeiro: Paz e Terra, 1995.

ADORNO, T. W. Teoria da Semicultura. Tradução RAMOS-DE-OLIVEIRA, N. et al.

Educação e Sociedade, ano XVII, n. 56, p. 388-411, dez. 1996.

ADORNO, T. W. Dialética Negativa. Rio de Janeiro: Jorge Zahar, 2009.

BASSANI, J. J.; VAZ, A. F. Técnica, corpo e coisificação: notas de trabalho sobre o tema da técnica em Theodor W. Adorno. Educ. Soc., Campinas, v. 29, n. 102, p. 99-118, Abr.2008. CHARAUDEAU, P. Langage et Discours. Paris: Hachette, 1983.

CHARAUDEAU, P. Uma Teoria dos Sujeitos da Linguagem. In: MARI, H.; MACHADO, I.; MELlO, R. (Orgs.). Análise do Discurso: Fundamentos e Práticas. Belo Horizonte:

NAD/FALE/UFMG, p. 23-38. 2001. .

COHN, G. Theodor Adorno. São Paulo: Ática, 1986.

DUARTE, R. Esquematismo e semiformação. Educação e Sociedade, Campinas, v. 24, n. 83, p. 441-4557, Aug. 2003.

GIROUX, H. Os Professores Como Intelectuais: rumo a uma pedagogia da aprendizagem. Porto Alegre: Artes Médicas, 1997.

GOLIOT-LÉTÉ, A.; VANOYE, F. Précis d'analyse filmique. Paris: Nathan, 1992.

HORKHEIMER, M. Teoria Tradicional e Teoria Crítica. In: Os Pensadores. São Paulo:

Nova Cultural, 1991.

HORKHEIMER, M; ADORNO, T. W. Conceito de Iluminismo. In: HORKHEIMER, M.

Teoria Tradicional e Teoria Crítica. Os Pensadores. São Paulo: Nova Cultural, 1991.

JAY, M. As Idéias de Adorno. São Paulo: Cultrix/Edusp, 1988.

KANT, I. Resposta à Pergunta: Que é esclarecimento? In: Textos Seletos (edição bilíngue).

Petrópolis: Vozes, 1985.

MAAR, W. L. Adorno, semiformação e educação. Educação e Sociedade., Campinas, v. 24, n. 83, p. 459-475, 2003.

REAd | Porto Alegre - Vol. 24 - No 3 - Setembro / Dezembro 2018 - p. 1-20 
MAAR, W. L. Introdução. In: ADORNO, T.W. Educação e emancipação. Rio de Janeiro: Paz e Terra, 1995.

MARANHÃO, C. S.; VILELA, J. R. P. X. A imanência entre a teoria crítica e a pesquisa empírica: contribuições para os estudos organizacionais. O\&S - Salvador, v. 24, n. 82, p. 476-490, Jul./Set. 2017.

MARANHÃO, C.; SANTOS, F. C. P.; GOUVEIA, P. N. Teoria Crítica e Didática: Um

Desafio para a educação contemporânea. Revista Eletrônica de Administraçãa, v. 24, n. 1, p. 129-148, 2018.

OFFE, C. Sistema educacional, sistema ocupacional e política de educação: contribuição a determinação das funções sociais do sistema educacional. Educação e Sociedade. Campinas: São Paulo, v.11, n.35, abr. p. 9-59. 1990.

OLTAMARI, A.P.; LOPES, F.T. Cinema, trabalho, organizações e sociedade: possibilidades e formação em administração. In: Anais do Congresso Brasileiro de Estudos Organizacionais - CBEO, 4. Anais... Porto Alegre, 2016.

PENAFRIA, M. Análise de filmes - conceitos e metodologias. VI Congresso SOPCOM, 2009. Disponível em: http://www.bocc.ubi.pt/pag/bocc-penafria-analise.pdf. Acesso em 27 de set. 2018.

PUCCI, B. Teoria Crítica e Educação. In: PUCCI, B. (org.) Teoria crítica e educação. A Questão da formação cultural na Escola de Frankfurt. Petrópolis: Vozes, 1994.

PUCCI, B. A Teoria da Semicultura e Suas Contribuições Para a Teoria Crítica da Educação. In: ZUIN, Antonio Álvaro Soares; PUCCI, Bruno; RAMOS-DE-OLIVEIRA, Newton (orgs) A educação danificada: contribuições à teoria crítica da educação. Petrópolis/São Carlos: Vozes/UFSCAR, 1998.

RAMOS DE OLIVEIRA, N. Theodor W. Adorno: quatro textos clássicos (traduções). São Carlos: UFSCAR, 1992.

RAMOS-DE-OLIVEIRA, N. Reflexões Sobre a Educação Danificada. In: ZUIN, A. A. S.; PUCCI, B.; RAMOS-DE-OLIVEIRA, N. (orgs) A educação danificada: contribuições à teoria crítica da educação. Petrópolis/São Carlos: Vozes/UFSCAR, 1998.

ZUIN, A. A. Seduções e Simulacros: Reflexões sobre Indústria Cultural, Reprodução e Resistência em Educação. São Carlos: UFSCAR, 1992.

REAd | Porto Alegre - Vol. 24 - No 3 - Setembro / Dezembro 2018 - p. 1-20 